\title{
Power equipment fault information acquisition system based on Internet of things
}

\author{
Ruilian Wang ${ }^{1}$ and Minghai Li2 ${ }^{2^{*}}$
}

\section{${ }^{*}$ Correspondence:}

jdjskfgs@xauat.edu.cn

${ }^{2}$ Xi'an University

of Architecture

and Technology,

Xi'an 710055, Shaanxi, China

Full list of author information

is available at the end of the

article

\begin{abstract}
With the advent of the Internet of things era, power equipment is gradually connected to the network, and its intelligent fault detection function provides greater help for the power industry. The purpose of this study is to design the power equipment fault information acquisition system of the Internet of things. This research is based on the equipment fault information collection system of the Internet of things and mainly studies the fault information collection method based on the Internet of things technology. Equipment fault data are generally time series data. In the analysis of equipment failure, the data before and after fault and before and after fault are analyzed. The abnormal state of equipment is associated with the data before and after the fault. Therefore, by analyzing the characteristics of the fault data and the equipment before and after the fault, a bidirectional recurrent neural network model based on LSTM is constructed. The method designed in this paper can not only improve the efficiency and speed of collection, but also can compare and collect fault information. The overall operation state of the power unit is improved accurately. The research results show that the company's low-voltage user acquisition success rate has reached more than 99\%. With the increase of time, the fault information collection efficiency can approach 99\%. It shows that the function of this research system is better, the economic loss of the company is reduced, and the management is optimized.
\end{abstract}

Keywords: Internet of things, Power equipment, Information collection, System design

\section{Introduction}

The fault of power equipment is usually dynamic and random. In order to ensure the normal operation of power equipment, it is necessary to detect the power equipment quickly and accurately. At the same time, the fault of power equipment must be predicted correctly and reasonably according to the detected information. Only this method can solve the existing hidden danger in time, avoid the continuous deterioration of power equipment status and reduce the accident rate. The characteristics of online monitoring are continuous monitoring and detection in operation, analysis and judgment of device status. In practical engineering, the application of state maintenance needs online monitoring. The appearance of state detection and diagnosis technology of power equipment is to adapt to the above development trend. By detecting the operation of

(0) The Author(s) 2021. Open Access This article is licensed under a Creative Commons Attribution 4.0 International License, which permits use, sharing, adaptation, distribution and reproduction in any medium or format, as long as you give appropriate credit to the original author(s) and the source, provide a link to the Creative Commons licence, and indicate if changes were made. The images or other third party material in this article are included in the article's Creative Commons licence, unless indicated otherwise in a credit line to the material. If material is not included in the article's Creative Commons licence and your intended use is not permitted by statutory regulation or exceeds the permitted use, you will need to obtain permission directly from the copyright holder. To view a copy of this licence, visit http:// creativecommons.org/licenses/by/4.0/. 
power equipment and analyzing the abnormal information of each equipment, we can obtain power as soon as possible [1]. At the same time, the potential equipment failure is predicted.

With the advent of the Internet of things era [2], power equipment is gradually connected to the network, and its intelligent fault detection function provides greater help for the power industry. The traditional power equipment fault information collection system has the problems of poor efficiency, slow fault information collection speed and incorrect information collection, which is difficult to cope with the network era of power equipment scale expansion [3]. For power companies, the collection system in the past is very wasteful, and the maintenance of hardware and software systems is also very difficult. If the fault information cannot be collected effectively and quickly, it will have a serious impact on the operation of the power group.

In the research of power equipment fault information acquisition system, Maximov $\mathrm{S}$ proposed a new method of power system equipment average life assessment based on two-parameter Weibull distribution. The method is suitable for complete and correct fault data. He uses the classical maximum likelihood estimation (MLE) to determine the distribution parameters. However, he proposed an estimation method based on asymptotic expansion, which overcomes the shortcomings of numerical or graphical techniques based on maximum likelihood estimation. By analyzing two right censored life datasets of three types of power equipment with different sample sizes, he proves that his method has higher accuracy than other estimators. His method is not stable [4]. Qiu $J$ in order to analyze the fault trend of power equipment more accurately, he improved the nonparametric regression method based on hierarchical proportional hazard model (PHM) [5] and established a failure rate model suitable for general power equipment. His model can maximize the use of equipment life cycle data as covariates, including power equipment manufacturers, in the hierarchical health status of equipment in the process; it is conducive to quantitative processing and classification of life cycle data. He uses more inspection events over a full cycle to predict potential risks and assess the health of the equipment. Then, he uses hierarchical nonparametric PHM method to establish a multi-type recurrent event specific failure model for interval censored competitive risk problems. Finally, a transformer is taken as an example to illustrate the modeling process. The accuracy of his method is not high [6]. Nozadian M H B studied the reliability and mean time to failure (MTTF) of semiconductor switches in series and in parallel under different failure rates. According to the different values of the reliability of series parallel structures in case of failure, he comprehensively compares the reliability of series parallel structures under different failure rates. According to the fault type and switch structure, the switch reliability of redundant structure is higher than that of other structures. His method lacks argument and persuasion [7]. The fault data of impregnated paper under DC pulsating voltage was studied experimentally by Li J. He obtained the fault data of the oil impregnated paper specimen through the constant pressure stress test and estimated the statistical distribution of the fault data using Weibull distribution. He used the exponential function (EF) and inverse power function to analyze the fault data of oil paper specimens obtained under pulsed DC voltage and DC and AC voltage alone. The performance of his method is evaluated by the fault data obtained from constant stress tests under different voltages [8]. His method is not practical [9]. 
This study first introduces the overall structure of the system and also describes the construction of fault information collection system based on the Internet of things, including the classification of power equipment status information, information acquisition methods and the establishment of induction layer. This study also describes the data acquisition requirements analysis and the life cycle management of power equipment based on Internet of things technology. This study describes the formula of relative evaluation standard. In this study, two electric power companies in our city are taken as the experimental objects, and different fault information collection is carried out respectively. Through the experimental results, the operation health status of power equipment is predicted and analyzed, the fault information collection status of the Internet of things is analyzed, and the accuracy and efficiency of the information acquisition system are analyzed [10].

\section{Power equipment fault information acquisition system and Internet of things technology}

\subsection{Overall system architecture}

In terms of architecture, the bottom layer of the system is composed of multiple hardware terminals. The hardware terminal is used to complete the information exchange between the system and the external environment. The upper layer of the system is the software system [11]. The software system can analyze information and data from the lowest level and save data. The core module has general problems, and the testability and maintainability of the system are relatively low $[12,13]$.

The system is very complex, including many modules, and the communication and data transmission between modules are more complex. All commercial processing functions of the system must be completed in the communication mode implementation class [14]. This includes the management of communication tasks, the sending and receiving of communication data, and the analysis of communication protocols. When multitasking is executed simultaneously, the upstream and downstream communication management of multiple devices is performed at the same time: The array is used as a method to handle the simultaneous execution of multiple tasks in the communication processing class and to record the current status of the devices in the system. Because of the internal integration of the system, the ability of the system to adapt to the changes of the external environment is relatively weak. After the communication mode is changed, the communication between modules needs to be reestablished. All program architectures need to be reused $[15,16]$.

Access server is the core of the whole system [17]. It is the communication center and business of the system to realize the integration and communication with all components, communication with hardware terminal, data processing and analysis, database storage and display driver. As shown in Fig. 1, the data acquisition flowchart.

As can be seen from Fig. 1, the system software adopts a distributed multi-layer structure including demonstration layer (client), including operator and commercial processing layer and commercial processing layer. Business dialogue between the implementation of the agreement. The external interface is the core business processing part of the whole system, the application service layer is the technical support of the business service layer, and the data layer is responsible for the centralized storage 


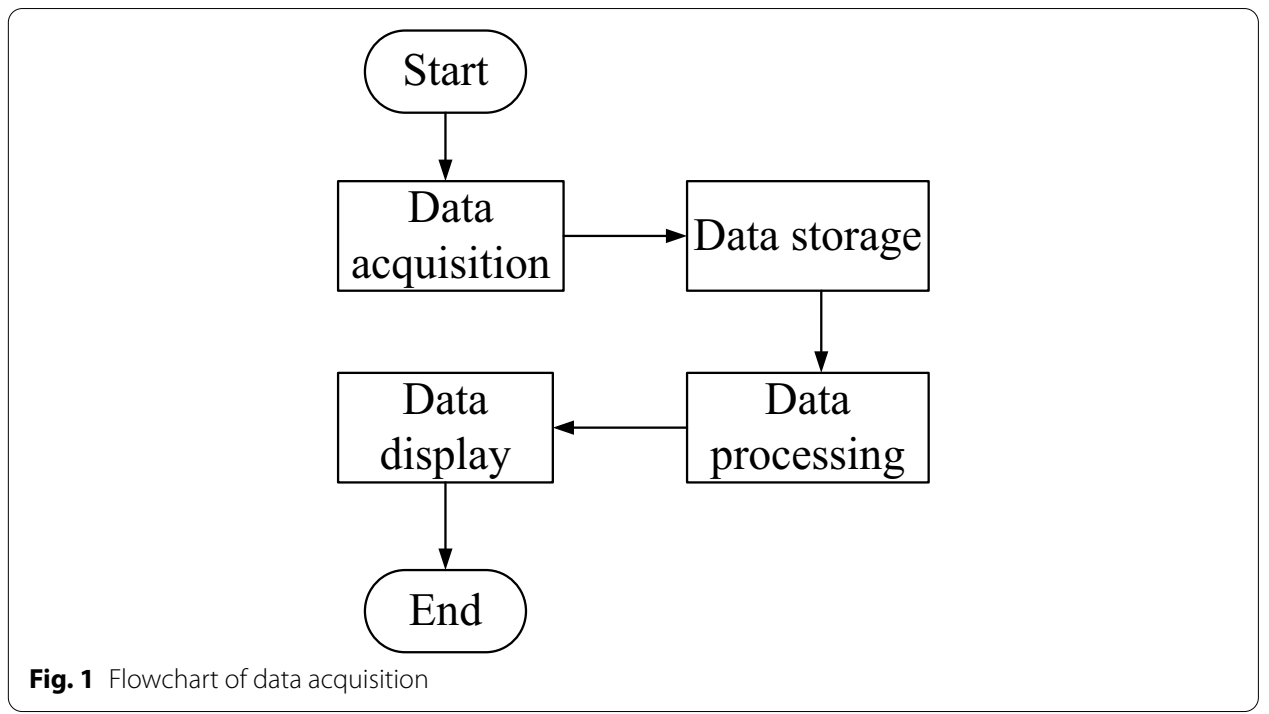

of the whole system data, and responsible for data optimization, data mining and other management $[18,19]$.

Data collection is to collect the current power consumption information of users in the practical application layer [20]. Data storage means that the data are collected and sent to the data storage platform. Data processing is the processing of stored data. Data display is to display the final data to users through the system interface. It realizes the process from collection, visualization to monitoring data source. At present, there are many problems in data collection, such as various data sources, large amounts of data, rapid changes, ensuring data reliability and how to face duplicate data [21].

\subsection{Construction of fault information collection system based on Internet of things}

The perceptual layer is similar to human senses and has the functions of recognizing, obtaining information and collecting necessary data information. In the existing Internet technology, two-dimensional code tag and reader, wireless RFID technology and reader, monitoring technology, global positioning system, various sensors, M2M terminal are more mature. First of all, the sensing layer obtains the data information of the tested equipment through various sensors and surveillance cameras, uses Bluetooth, RFID, two-dimensional code and other technologies for short-distance communication and inputs the local information processing device. The important problems that need to be solved in the sensing layer are the list of data to be collected, the improvement of detection technology and the short-range wireless transmission communication.

(1)Classification of state information of power equipment

All kinds of information of substation equipment, such as sound, light, electricity and image, can reflect the whole life cycle status of the equipment from all aspects, 
so the status information of substation equipment must contain a variety of data. According to the test data, observation records and other production processes of power system operators, it can be divided into three types: application information, operation information and maintenance test information [22, 23].

\section{Information before commissioning}

The information before operation is usually collected by the technical department of the operation and maintenance management department of the power company. The infrastructure and materials departments adjust and collect the units before they start up and transfer them to the production department after operation. In the production management system, the technical account of substation equipment and the drawings of expansion project are collected by the application management department. The related module is a production management system designed to save this information. Factory test report, handover test report, installation acceptance record and other information can be used. As the initial value of the equipment status information, the information management module of the production management system of the application layer is input from the maintenance department [24].

2. Operation information

Application information mainly includes equipment inspection, maintenance, fault trigger, defect record, fixed real-time detection and mobile real-time detection data, as well as information related to harsh working conditions. In the running state of the equipment, through the inspection of the management personnel and the daily maintenance of the overhaul personnel, the corresponding status information of the equipment can be obtained through records, which is collected, especially input into the production management system of the application layer according to the plan. Mobile real-time detection and fixed real-time detection and other test data will be collected through the Internet of things system and input into the information management system.

3. Maintenance test information

Maintenance test information mainly includes periodic test report, diagnostic test report, special inspection record, defect removal record and maintenance report. Maintenance test unit is responsible for the collection, classification and input of production management information system. If the machine is returned to the factory for maintenance, it is necessary to obtain the repair report and relevant information from the manufacturer and input it $[25,26]$.

\section{(2) Access to information}

Patrol inspection of various types of voltage levels of substation equipment in power system, technical specifications of test items, servicing period, servicing items, etc., according to the legal provisions, the network system which mainly combines state protection objects with mobile real-time detection can form a collection method.

\section{Inspection}


According to the operation status of substation equipment, the management department shall carry out daily inspection and various equipment inspection. The inspection content is determined by the characteristics of the equipment and the characteristics to be collected. With the inspection characteristics of various equipment, it is convenient for daily management. The characteristics of the daily inspection also need to develop a cycle. In addition to daily inspection, other special inspections can be carried out according to the technical documents of different equipment. In addition to daily inspection, special inspection and inspection should be carried out at specific time and weather such as typhoon season inspection, strong wind and cold weather inspection. All types of inspections require electronic documentation for recording and input into the application layer [27, 28].

\section{Experiment}

The power failure test of various equipment is an important information source of machine status information, which can be divided into regular examination and diagnostic examination. Type tests carried out at regular intervals. Adjust the cycle according to the status and maintenance judgment of the machine obtained by the application layer. Diagnostic tests are only carried out when the equipment is abnormal or suspected to be abnormal [29].

3. Fixed live detection (online monitoring)

Stable real-time detection refers to the method of continuous or regular detection by using sensors set in or near the equipment body during normal operation of substation [30].

\section{(3) Establishment of induction layer}

Sensor layer information can be divided into professional patrol, mobile site detection and fixed site detection. Professional patrol is patrolled by operation and maintenance personnel and reported to handheld terminal and uploaded to PMS. The mobile real-time detection data will be transmitted to the handheld device through the portable detection device through Bluetooth. The fixed real-time detection can be directly uploaded through the online monitoring module of substation and transmission equipment.

\subsection{Data acquisition demand analysis}

The main function of the system is to realize the complete collection of power consumption data of all customers, including real-time collection of voltage, current, power and other data. The collection of users is classified as follows. The purpose of power consumption information collection system is to enable all users to collect power consumption information in real time. Users here include large, medium and small special transformer users, low-voltage single-phase users, three-phase users and public distribution transformer evaluation [31, 32]. 
Data collection can be divided into automatic collection and manual collection. During the collection task, the main data collected by the terminal are: voltage data, current data, meter reading data, load data and other related data.

The collected data mainly include the following contents: basic information includes current instrument data, total effective power, total invalid power, current / day freeze; maximum demand: the maximum demand of effective/invalid power, generation time and current value; current and voltage value: current curve data, voltage curve data and load curve data; and power data: data curve of measurement point, effective power and invalid power [33, 34].

1. Automatic acquisition task

Constitute an automatic collection task, according to the data collection table to read data, curve data, statistical data and other related records in a specific period.

2. Collection quality analysis

By comparing the daily collection tasks, analyze the success rate of collection, and judge whether the automatic data collection is normal.

3. Data call test

Data calls can obtain specific interrupt or remote graph data by manually obtaining data collection.

\subsection{On line monitoring technology of circuit breaker category}

1. Mechanical part monitoring.

Monitoring includes switching time, coil waveform, contact travel and speed, and vibration waveform. The grid which can collect the displacement signal is set in the operation part of the circuit breaker. The speed displacement is converted into electrical signal through the relative movement of the grid and the circuit breaker, and the displacement, speed and time of the circuit breaker action are obtained through data processing. Then the displacement and opening and closing velocity can be calculated.

\section{Control part monitoring.}

Monitor the action time of the auxiliary contact and the action state of the control unit.

\section{Electrical monitoring.}

The switch action of circuit breaker is usually realized by electromagnet. When the control current flows through the coil of the electromagnet, the electromagnet will send out electromagnetic force and lead the core into the circuit device. The current flowing in the switch coil contains a lot of transmission information that can be detected. Usually, the current monitoring sensor uses Hall sensor, which synchronizes the relative time of fault with the current waveform to judge the fault symptoms. 


\subsection{Life cycle management of power equipment based on Internet of things technology}

1. In the initial stage of construction, the construction cost of power equipment increases, but as an ancillary equipment, the Internet of things technology needs certain material support, so the initial construction cost will inevitably increase. However, under the premise of large-scale publicity and application of digital substation and intelligent substation, this cost is covered by the cost of some construction machinery, which has no significant impact on the initial cost [35].

2. Greatly improve the operation level and service life of the power supply device. In this article, from the point of view of the Internet of things to monitor and maintain the state of power machines, the role of Internet technology on things is explained. The core is to improve the operation level of the machine and shorten the maintenance time of power failure [36].

3. Reduce machine maintenance costs and labor costs. With the improvement of automation level, the proportion of labor cost in power system is bound to be smaller, but now the labor cost of individuals in society is increasing every year, and the power system is very dangerous, which cannot be ignored. The cost is very serious. Through the development of Internet technology, online condition monitoring and reasonable state maintenance plan, labor consumption and working environment reliability are greatly reduced. On the other hand, the reduction of the maintenance cost of the machine is also related to the improvement of the reliability and quality of the power supply. In this way, the power industry has brought benefits, and social and economic benefits have also increased.

\subsection{Relative evaluation criteria}

When the measured value of the monitoring parameter exceeds the specified threshold range or the specified limit value, the action state of the unit will change, and the abnormality may occur. In case of abnormal conditions, the machine does not necessarily fail. In addition, due to the change of the operation conditions of the unit, the monitored parameter values may change. On the contrary, when the monitoring data are within the normal action threshold, the unit also has abnormal state. Therefore, other evaluation criteria can be imported. Relative evaluation criteria. Relative evaluation benchmark refers to that for the same monitoring quantity of the same unit, the normal value in a certain period is taken as the reference value or health value, and the working condition of the unit is evaluated and analyzed by comparing the actual value with the reference value.

\section{Determination of evaluation benchmark value}

According to the statistical theory, if the sample condition is large, the average value of the sample can be regarded as the theoretical average value. Therefore, in the case of large accumulation of unit data, the average value of characteristic quantity can be solved as the benchmark value of soundness evaluation 


$$
\begin{aligned}
& \bar{X}=\frac{\left(x_{1}+x_{2}+\cdots+x_{n}\right)}{n} \\
& P_{t}=\frac{P_{\max } \times D L}{K} \times \ln \left[\frac{P_{\max }+a \times 0.47 \times K \times(1-r) \times \frac{Q}{D L}}{P_{\max }+a \times K \times(1-r) \times \frac{Q}{D L} \times e^{(-K \times L A I)} \times 0.47}\right] \\
& A_{p}=\left\{\begin{array}{l}
0.1822 \times \ln F_{s t}+1.29, C K \\
0.0896 \times \ln F_{s t}+0.91, T 100 \\
0.0993 \times \ln F_{s t}+0.71, T 150
\end{array}\right.
\end{aligned}
$$

2. Determination of evaluation and early warning interval

The structure of turbine unit is more complex, and the random error of reference value is composed of many factors such as variation and random interference. However, random errors usually have the characteristics of statistical distribution and generally follow the normal distribution. Therefore, the combination of the leyit criteria can lead to the evaluation of warning thresholds

$$
\begin{aligned}
& X_{c}=\bar{X} \pm 3 \sigma \\
& A F_{s t} Y=\left\{\begin{array}{l}
\sum_{i=1}^{n} F_{s t_{i}}, F_{s t_{i}}<Y \\
\sum_{i=1}^{n}\left(F_{s t_{i}}-Y\right), F_{s t_{i}} \geq Y
\end{array}\right. \\
& F_{s t}=\frac{\left[O_{3}\right]}{r_{h}+r_{s}} \\
& Y=\alpha \times P_{t}
\end{aligned}
$$

$Y$ is the damage explanation value of the absorbed.

$\sigma$ is the standard deviation.

$$
\sigma=\sqrt{\frac{1}{n-1} \sum_{i=1}^{n}\left(X_{i}-\bar{X}\right)^{2}}
$$

For each characteristic quantity of the unit, its reference value and early warning area can be constructed into a health sample by operating performance data. During normal operation of the device, it can be seen from the statistical rule that the probability of the measured point data within the normal sample interval is $99.73 \%$. When the unit measurement point data exceeds the healthy area of the sample, the probability of abnormal machine is $99.73 \%$. Therefore, from the perspective of statistical theory, this method can be used to construct the health baseline and early warning area of equipment.

\subsection{Principal component analysis}

Principal component analysis (PCA), also known as principal component analysis (PCA) or principal component analysis (PCA), is a very popular statistical data analysis method 
to find as few orthogonal vectors as possible to represent the data information characteristics of multivariate data.

PCA tries to regroup the original variables into a new group of independent comprehensive variables. At the same time, according to the actual needs, a few less comprehensive variables can be taken out to replace the original variables, and the combination can reflect the information of the original variables as much as possible. It is a common method to deal with dimension reduction mathematically. The general method is to transform the linear orthogonal transformation into uncorrelated new orthogonal variables, and use the variance of each group to distinguish. That is, the larger the variance of Y1 (the first selected linear combination), the more information Y1 contains. If $\mathrm{Y} 1$ is the largest variance of all linear combinations, then $\mathrm{Y} 1$ is the first principal component.

The operation steps of PCA are as follows.

1. Get the raw data.

2. Subtract the mean. For PCA to work well, first calculate the average value of each dimension, and then subtract the mean value of each dimension from each sample to get a difference, thus a new dataset can be obtained.

3. The covariance matrix is calculated. Covariance operation is performed on the dataset obtained in the second step.

4. The eigenvalues and eigenvectors are calculated. The covariance matrix obtained in the third step. It must be a square matrix, so the eigenvalues and eigenvectors of the matrix can be obtained by using the knowledge of linear algebra.

5. Select several main components to construct the new space. In fact, the feature vector corresponding to the maximum eigenvalue is printed as the principal component of the dataset, which contains a large amount of information.

6. Reconstruct the data.

\section{Experimental design of power equipment information acquisition system of IOT}

\subsection{Experimental data}

In this study, two power companies in our city are selected as the experimental research objects, and the data collected by the power equipment fault information collection system of the two companies before are compared. Then, one of them is taken as the experimental group, and the traditional fault information collection system of power equipment is replaced by the intelligent system of Internet of things. After one year's use, the data collection amount, accuracy and speed of the two companies are analyzed.

\subsection{Experimental steps}

First of all, the design framework of fault information collection system based on the overall structure sets the experimental parameters to provide data for the experiment. Select the company, let the company's employees upload power equipment fault information at the same time, record the information collection speed in the system, and perform data analysis. The former design of fault information collection for power equipment is compared with the system, and the experimental results are obtained. 
According to the above experimental contents and results, the experimental conclusion is drawn.

\subsection{Experimental background and materials}

State selection: After obtaining the relevant data of power grid equipment status through various monitoring methods, the data are further analyzed and processed to generate a model that can directly reflect the working state of the corresponding power grid equipment, and then the power grid equipment needs to generate the corresponding model data. Combine historical data, such as inspection and maintenance records, to produce a scientific and reasonable system to evaluate the status of grid equipment and reasonable combination. Results of the evaluation system can guide the maintenance of power grid equipment accurately and timely.

According to the status data of online detection, operation status, abnormality, test results and maintenance status of transmission network equipment, the health status of the equipment is scored. The score range is $0-100$. Full score means that all information data of the equipment are compared with the initial value when the factory leaves the factory. If the attention value is near or far away, the grid equipment is in good condition, and the working conditions are not good, so it is not necessary to repair. A score of 0 means that the grid device must be repaired immediately, and the score of other conditions of the equipment is between 0 and 100 .

\subsection{Power calculation of power equipment}

In ship DC power system, the output angular speed of diesel engine is only connected with the rotor of rectifier generator coaxially, that is to say, it provides prime power and only receives electromagnetic torque of rectifier generator, that is, it only cares about the speed and torque of diesel engine. Therefore, the internal characteristics of the diesel engine are ignored and simplified, and a diesel engine model with certain accuracy suitable for marine DC power system is constructed. In diesel engine, the mathematical relationship between effective power, output torque and average effective pressure and speed is as follows:

$$
\begin{aligned}
& N_{e}=\frac{2 p_{e} V_{l} n}{60 \tau}=\frac{p_{e} V_{l} n}{30 \tau}=K_{1} p_{e} n \\
& M_{1}=\frac{60}{2 \pi} \times \frac{N_{e}}{n}=9.55 \frac{N_{e}}{n}=K_{2} p_{e} \\
& D L=\left\{\begin{array}{l}
0.133 \times 57.3 \times \arctan \frac{\sqrt{1-\left[-\tan \left(\frac{L T}{57.3}\right) \times \tan (S L)\right]^{2}}}{-\tan \left(\frac{L T}{57.3}\right) \times \tan (S L)} \\
0.133 \times\left\{180+57.3 \times \arctan \frac{\sqrt{1-\left[-\tan \left(\frac{L T}{57.3}\right) \times \tan (S L)\right]^{2}}}{-\tan \left(\frac{L T}{57.3}\right) \times \tan (S L)}\right\}
\end{array}\right.
\end{aligned}
$$


where $N_{e}$ is the effective power of the diesel engine: $n$ is the speed of the diesel engine; $\tau$ is the stroke coefficient; $p_{e}$ is the average effective pressure; $V_{l}$ is the working volume of the cylinder; $M_{1}$ is the output torque of the diesel engine: $K_{1}=V_{l} / 30 \tau ; K_{2}=0.955 K_{1}$.

If the set of all variables is $X$, the set of evidence variables is $E$, and the set of query variables is $Q$ :

$$
\begin{aligned}
& p(Q \mid E=e)=\frac{p(Q, E=e)}{p(E=e)} \\
& d\left(x_{i}\right)=\sum_{i=1}^{n} d\left(x_{i}, x_{j}\right)
\end{aligned}
$$

Its expression is as follows:

$$
\begin{aligned}
& \min _{i}=\min _{i}-k \times \text { steplen }(i) \\
& \max _{i}=\max _{i}-k \times \operatorname{steplen}(i) \\
& K \equiv\left(K^{2} / K\right)=2
\end{aligned}
$$

$K$ is the average node degree in the network.

$$
P_{I}(K)=\sum_{K_{0} \geq K}^{k} P\left(K_{0}\right)\left(\begin{array}{c}
K_{0} \\
K
\end{array}\right)(1-H)^{K} H^{K_{0}-K}
$$

Using the new degree distribution as in Eq. (2), we can get time (3) and (4):

$$
\begin{aligned}
& K_{1}=K_{0} *\left(1-H_{Y}\right) \\
& K_{1}^{2}=K_{0}^{2}\left(1-H_{R}\right)^{2}+K_{0}^{2} H_{R}\left(1-H_{R}\right)
\end{aligned}
$$

Combined with the zero-boundary state criterion of network collapse, we can get:

$$
K_{1}^{2} / K_{0}=K_{1}^{2} / K_{0}\left(1-H_{R}\right)+H=2
$$

Let $K_{0}=K_{0}^{2} / K_{0}$ be calculated from the degree distribution in the initial network:

$$
\int_{-\infty}^{+\infty} P(K) D K=\int_{-\infty}^{+\infty} C K^{-\lambda} D K=1
$$

It can be derived from formula (6):

$$
C=(\lambda-1) m^{\lambda-1}
$$

$K_{0}$ is calculated as:

$$
K_{0}=K_{0}^{2} / K_{0}=\sum_{K_{\mathrm{MIN}}}^{K_{\mathrm{MAX}}} K_{0}^{2} P K_{0} / \sum_{K_{\mathrm{MIN}}}^{K_{\mathrm{MAX}}} K_{0} P K_{0}
$$


Putting $P K_{0}=C K_{0}^{-\lambda}=(\lambda-1) M^{\lambda-1} K_{0}^{-\lambda}$ into the above formula, we can get:

$$
K_{0}=\int_{M}^{K_{\mathrm{MAX}}} K_{0}^{2}(\lambda-1) M^{\lambda-1} K_{0}^{-\lambda} D K_{0} / \int_{M}^{K_{\mathrm{MAX}}} K_{0}(\lambda-1) M^{\lambda-1} K_{0}^{-\lambda} D K_{0}
$$

\subsection{Equipment scoring method}

State selection: After obtaining the relevant data of power grid equipment status through various monitoring methods, the data are further analyzed and processed to generate a model that can directly reflect the working state of the corresponding power grid equipment, and then the power grid equipment needs to generate the corresponding model data. Combine historical data, such as inspection and maintenance records, to produce a scientific and reasonable system to evaluate the status of grid equipment and reasonable combination. Results of the evaluation system can guide the maintenance of power grid equipment accurately and timely.

According to the status data of online detection, operation status, abnormality, test results and maintenance status of transmission network equipment, the health status of the equipment is scored. The score range is $0-100$. Full score means that all information data of the equipment are compared with the initial value when the factory leaves the factory. If the attention value is near or far away, the grid equipment is in good condition, and the working conditions are not good, so it is not necessary to repair. A score of 0 means that the grid device must be repaired immediately and the score of other conditions of the equipment is between 0 and 100 .

\section{Collection and analysis of power equipment fault information in Internet of things system}

\subsection{Test results and analysis}

By programming the algorithm, the traditional robust optimization model considering wind power integration is solved when the confidence interval of wind power output is $66.3 \%, 86.6 \%, 95.4 \%$ and $99.74 \%$. Table 1 shows the unit operating costs under four conditions. Table 2 shows the unit optimal scheduling table at $66.3 \%$ confidence level.

From Tables 1 and 2, it can be seen that with the increase of confidence level of wind power output confidence interval, the unit operation cost is on the rise, and the economy of unit combination scheme becomes worse. With the improvement of confidence level of wind power output confidence interval, the number of start-up units of traditional robust unit commitment model increases, the robustness of unit commitment scheme is enhanced, and the ability to cope with wind power fluctuations is improved.

With the change of the confidence interval of wind power output, the economy and robustness of the unit commitment scheme based on the traditional robust unit commitment model show a trend of ebb and flow. When the economy is good, the

Table 1 Unit operation under different confidence levels under traditional model

\begin{tabular}{lllll}
\hline Confidence level & $66.3 \%$ & $86.6 \%$ & $95.4 \%$ & $99.74 \%$ \\
Unit operation cost & 539,330 & 542,990 & 547,760 & 555,650 \\
\hline
\end{tabular}


Table 2 Unit optimal scheduling table at $66.3 \%$ confidence level

\begin{tabular}{lllllllllllllllllll}
\hline$N$ & $1-24 \mathrm{~h}$ & 110 \\
\hline 1 & 1 & 1 & 1 & 1 & 1 & 1 & 1 & 1 & 1 & 1 & 1 & 1 & 1 & 1 & 1 & 1 & 1 & 1 \\
2 & 1 & 1 & 1 & 1 & 1 & 1 & 1 & 1 & 1 & 1 & 1 & 1 & 1 & 1 & 1 & 1 & 1 & 1 \\
3 & 0 & 0 & 0 & 0 & 0 & 0 & 1 & 1 & 1 & 1 & 1 & 1 & 1 & 1 & 1 & 1 & 1 & 0 \\
4 & 0 & 0 & 0 & 0 & 1 & 1 & 1 & 1 & 1 & 1 & 1 & 1 & 1 & 1 & 1 & 1 & 1 & 0 \\
5 & 0 & 0 & 0 & 0 & 0 & 1 & 1 & 1 & 1 & 1 & 1 & 1 & 1 & 1 & 1 & 1 & 1 & 0 \\
6 & 0 & 0 & 0 & 0 & 0 & 1 & 1 & 1 & 1 & 1 & 0 & 0 & 0 & 1 & 1 & 1 & 1 & 0 \\
7 & 0 & 0 & 0 & 0 & 0 & 0 & 0 & 1 & 1 & 1 & 0 & 0 & 0 & 0 & 0 & 0 & 0 & 0 \\
8 & 0 & 0 & 0 & 0 & 0 & 0 & 0 & 0 & 0 & 0 & 0 & 0 & 0 & 0 & 0 & 0 & 0 & 0 \\
9 & 0 & 0 & 0 & 0 & 0 & 0 & 0 & 0 & 0 & 0 & 0 & 0 & 0 & 0 & 0 & 0 & 0 & 0 \\
10 & 0 & 0 & 0 & 0 & 0 & 0 & 0 & 0 & 0 & 0 & 0 & 0 & 0 & 0 & 0 & 0 & 0 & 0 \\
\hline
\end{tabular}

Table 3 Types of generator faults

\begin{tabular}{ll}
\hline Fault type & Fault category \\
\hline Electrical failure & Stator winding short circuit \\
& Broken stator wire \\
Mechanical failure & Stator hydro junction failure \\
& Rotor unbalance \\
Cooling system failure & Air gap eccentricity \\
& Shafting misalignment \\
& Leakage of stator winding \\
& Local blockage of ventilation duct
\end{tabular}

robustness of unit commitment scheme becomes worse, and the ability to deal with wind power fluctuation is weakened; when the robustness is good, the economy becomes worse. Therefore, there must be an optimal wind power output confidence interval, which makes the robustness and economy of the proposed unit commitment scheme reach the best compromise. However, the traditional robust unit commitment model considering wind power integration usually relies on experience or subjective intention to select the confidence interval of wind power output, which is lack of theoretical basis and the rationality of the proposed unit commitment scheme is also deficient.

\subsection{Main fault analysis of electric equipment engine}

The generator is usually composed of end cover, stator, rotor, brush device, leadout box, bearing and other components. The stator is composed of frame, main coil, commutation core, commutation coil, compensation winding, connecting wire and lead wire. The rotor is composed of rotor core, rotor winding, commutator, fan and shaft. The stator and rotor are connected and assembled by bearing and end cover, forming the main functional parts of the generator. As shown in Table 3, the main fault types of power equipment. 


\subsubsection{Fault diagnosis parameter information}

1. On line monitoring information: vibration monitoring

In this method, the vibration sensor is used to monitor the vibration of the motor bearing or frame. Because the vibration frequency of different faults is different, the vibration frequency can be compared with the known fault frequency to find the fault location and fault nature. The limitation of vibration monitoring is: For motors, the installation position of sensors is very few; on the other hand, the vibration frequency is very easy to be interfered by the outside, and the vibration intensity range is wide. In the complex external environment, there are many influencing factors, so it is difficult to accurately judge the corresponding fault; in addition, the fault type and vibration frequency are many to many It is difficult to distinguish the relationship.

\section{Electrical test information}

Discharge monitoring includes end discharge, internal discharge of motor insulation and slot discharge. When the discharge monitoring exceeds the warning value, the equipment maintenance shall be carried out. The axial magnetic flux leakage and shaft voltage monitoring will cause the increase of axial magnetic flux leakage flux and shaft voltage in case of fault, so the fault can be judged. Temperature monitoring is to detect the temperature of stator, bearing and other parts by temperature sensor to identify the fault. Due to the limitation of the position and number of sensors, it is difficult to reflect the actual heating position of the fault, so it is difficult to realize fault location.

\subsection{Prediction and analysis of operation health status of power equipment}

In the experiment, the $\mathrm{x}$-direction vibration data of the guide bearing group are selected. However, due to the high sampling frequency of the measuring points, a part of the data is intercepted in order to verify the model method. In the experiment, 2500 groups of data were selected and grouped according to 10 data. The average value of each dataset was taken as the new measurement point data, and a total of 250 groups of data were calculated. Figure 2 shows the time sequence display of measurement point data after recombination.

A total of 250 groups of data were divided into two parts. The first group of 200 groups of data was used as training data, the last 20 groups of data were used as validation data, and ARIMA model was used as control model. Figure 3 shows the results of forecasting data using ARIMA model and hybrid prediction model proposed in this section.

Figures 2 and 3 show that ARIMA prediction results are better than ARIMA-based hybrid and SVR prediction models. According to the combination forecast, the residual error is small, which indicates that the prediction result of the model is excellent. Therefore, the equipment is predicted by the model parameters related to vibration and then analyzed by asking the pendulum area, so as to achieve the goal of evaluating the indirect health status of the equipment. 


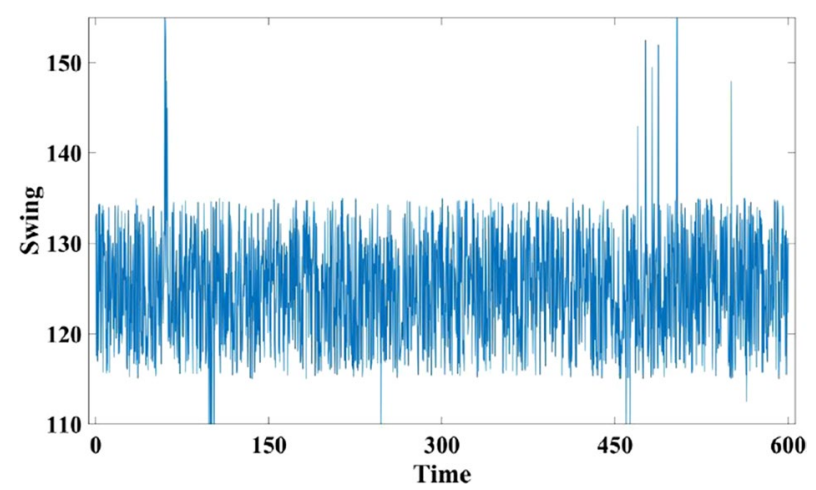

Fig. 2 Sample data of measuring points after grouping

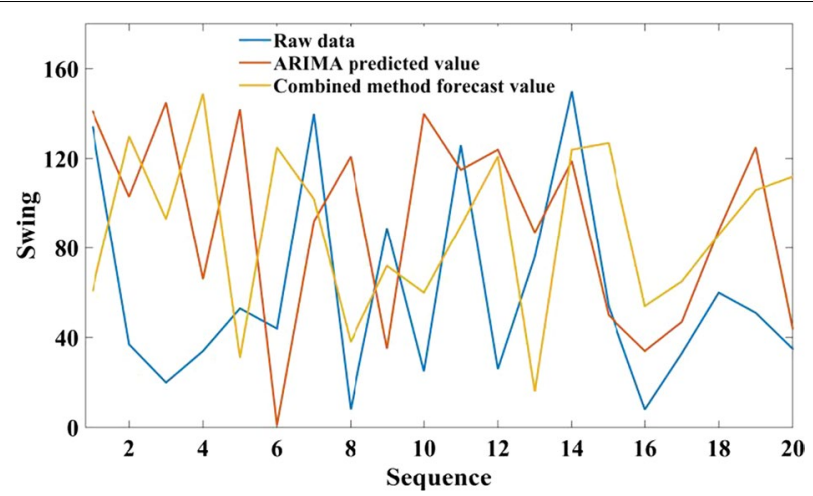

Fig. 3 Model prediction results

Table 4 Data collection of various users

\begin{tabular}{llll}
\hline Category & $\begin{array}{l}\text { Households (ten } \\
\text { thousand) }\end{array}$ & $\begin{array}{l}\text { Acquisition success } \\
\text { rate (\%) }\end{array}$ & $\begin{array}{l}\text { Application } \\
\text { ratio (\%) }\end{array}$ \\
\hline Low voltage data acquisition & 2084 & $>99$ & 98 \\
Public transformer data acquisition & 37.65 & $>99.5$ & 98 \\
Data acquisition of special transformer & 19.84 & $>99.5$ & 98 \\
\hline
\end{tabular}

\subsection{Analysis of power equipment fault information collection in the Internet of things}

All kinds of user data acquisition are shown in Table 4.

As shown in Table 4, as long as it is a local company, based on the acquisition, application and maintenance research, optimize the parent station strategy, improve the diversification of communication channels and network modes, gradually convert the old equipment and upgrade the communication module, and basic file management, fault collection, correct location, closed-loop processing and other solutions. At present, the company's success rate of collecting low-voltage users has reached more than 99\%, especially the collection success rate of public transformers has reached $99.5 \%$, and the recovery success rate of remote control power supply has reached more than $90 \%$. The 

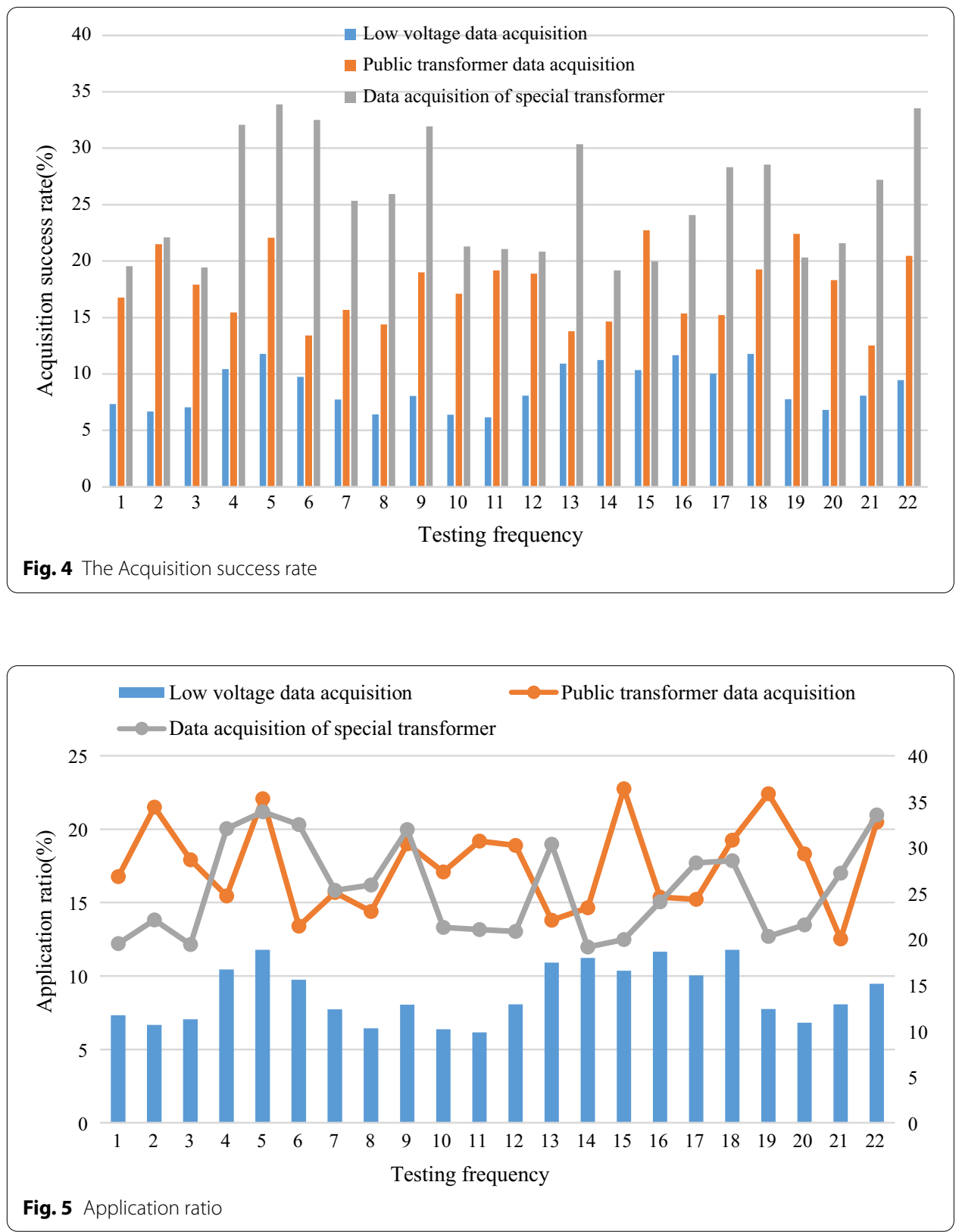

automatic collection of more than 20 million sets of electric energy meters has been realized, and the labor force of 50,000 people has been saved; the instructions for power outage and power restoration of 14,424,100 times have been issued normally. The acquisition success rate is shown in Fig. 4. Application ratio is shown in Fig. 5.

\subsection{Accuracy analysis of power equipment fault information acquisition system of Internet of things}

Firstly, the construction of bidirectional cyclic neural network structure based on LSTM is realized by tensorflow. The initial network parameters are randomly given by tensorflow according to the set loss function and network optimization algorithm, and the 


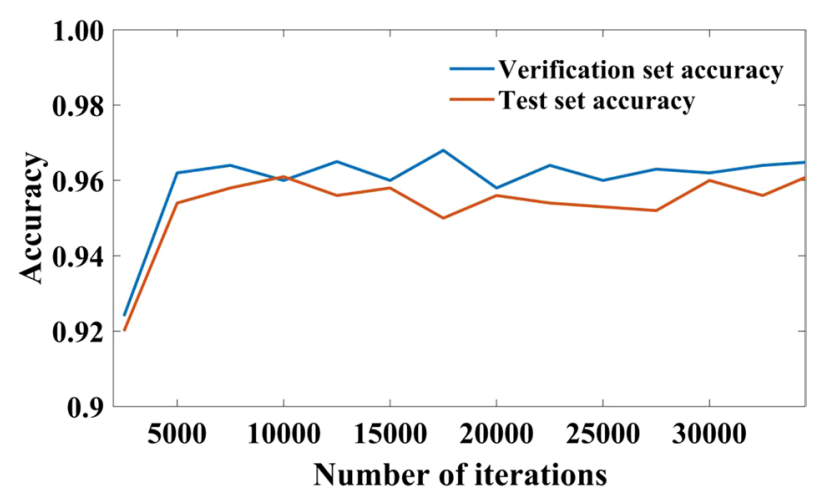

Fig. 6 The relationship between the accuracy of the system and the number of iterations

Table 5 Experimental classification results

\begin{tabular}{lllll}
\hline Algorithm & Classification & Accuracy (\%) & Recall (\%) & F1 value (\%) \\
\hline KNN & High-risk & 78.2 & 81.6 & 75.7 \\
& Low risk & 64.8 & 63.6 & \\
Invalid & 79.0 & 82.7 & \\
Crack & 78.6 & 82.9 & 86.3 \\
SVM & High risk & 86.6 & 87.8 & \\
& Low risk & 89.2 & 88.6 & \\
IOT approach & Invalid & 86.8 & 90.4 & \\
& Crack & 79.8 & 80.5 & \\
& High-risk & 98.0 & 97.3 & \\
& Low risk & 94.9 & 96.6 & \\
& Invalid & 97.9 & 95.2 & \\
\hline
\end{tabular}

learning rate $R /=0.05$ is set. The following experimental process is used for the experiment. The model is basically stable after 8000 repetitions. The relationship between the accuracy of test set data and verification set data and the number of iterations is shown in Fig. 6.

As shown in Fig. 4, if the number of iterations increases, the accuracy of both verification and test sets will be stable at about $96 \%$. The accuracy of verification group is slightly higher than that of test group. The surf IOT system works efficiently.

In order to further verify the accuracy of the fault information collection system, SVM is selected as control models in the experiment. The purpose of the three algorithms is to achieve the accuracy of four kinds of labels, that is, four kinds of analysis results: high risk, low risk, inefficiency, destruction, recall rate and F1. The experimental classification results such as scores are shown in Table 5 .

The experimental results in Table 5 show that the bidirectional current neural network based on this white paper has higher accuracy than SVM and KNN models, which verifies the applicability of the current neural network structure in the field of fault diagnosis. When dealing with sequence fault data, the processing ability of deep learning network structure is better than that of traditional shallow network structure. 


\subsection{Efficiency analysis of power fault information acquisition system of Internet of things} The efficiency of the former fault information collection system is compared with that of the object-based Internet environment. The comparison results are shown in Fig. 7.

As can be seen from Fig. 7, the power equipment fault information collection system based on the Internet of things improves the judgment performance of fault information and the efficiency of fault information collection. With the increase of time, the efficiency of fault information collection is different from that in the past, which can be close to $99 \%$. Compared with the system, this design is more reasonable and valuable.

Compared with the previous system, it can collect fault information faster and ensure the correctness of information collection. The power equipment fault information collection system based on the Internet of things has efficient information collection efficiency and high-speed information collection speed, which can realize multiple fault information collection and processing, and lay a solid foundation for the future information collection system design.

\section{Conclusion}

This research is based on the equipment fault information collection system of the Internet of things and mainly studies the fault information collection method based on the Internet of things technology. Equipment fault data are generally time series data. In the analysis of equipment failure, the data before and after fault and before and after fault are analyzed. The abnormal state of equipment is associated with the data before and after the fault. Therefore, by analyzing the characteristics of the fault data and the equipment before and after the fault, a bidirectional recurrent neural network model based on LSTM is constructed. This is more accurate than the previous machine learning diagnosis method.

With the advent of the Internet of things era, power equipment is gradually connected to the network, and its intelligent fault detection function provides greater help for the power industry. The traditional power equipment fault information collection system has the problems of poor efficiency, slow fault information collection speed and incorrect information collection, which is difficult to cope with the network era of power equipment scale expansion. For power companies, the traditional collection system is not only a waste of money, but also difficult to achieve hardware and software system

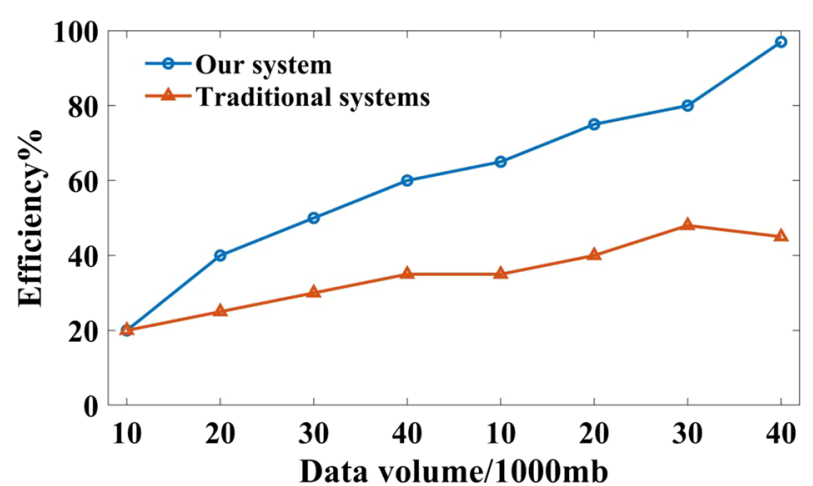

Fig. 7 Efficiency comparison of two acquisition systems 
maintenance. The method designed in this paper can not only improve the efficiency and speed of collection, but also can compare and collect fault information. The overall operation state of the power unit is improved accurately.

Power companies can reduce the economic losses of enterprises through real-time data collection, accurate analysis, online monitoring of abnormal problems, active learning, processing equipment failure, detection of electricity theft and other abnormal conditions. The application of the system not only improves the application ability and profitability of users, but also improves the intelligent management and high-quality service level of power companies. It is an important means to catch up with the construction of intelligent grid. In order to ensure the effectiveness of information collection, the control strength of the collection system can be adjusted when the hardware system is designed by circuit reset module. Compared with the previous system design, it can be analyzed that the system designed in this investigation has good fault information collection function and information collection, to provide strong support for the expansion of China's power industry.

Due to the limitation of time, only the generator is selected to realize the fault diagnosis function, and the fault monitoring and early warning of other equipment such as transformer, capacitive equipment, lightning arrester, power cable and so on can be further designed and implemented, and a comprehensive fault monitoring and early warning system can be further completed. Different devices are suitable for different diagnosis algorithms. Further research and test should be carried out on the diagnosis algorithms. In addition, the functions of the system should be further improved according to the actual situation. The equipment monitoring module should be further improved. In addition to browsing the parameter information and inputting data, the next goal should be to realize the automatic data collection and uploading to the server.

Abbreviations

IOT: Internet of Things; MLE: Maximum likelihood estimation; PHM: Peptide histidine-methionine; MTTF: Mean time to failures; EF: Extremely fine; DC: Direct current; AC: Alternating current.

Acknowledgements

The authors thank the editor and anonymous reviewers for their helpful comments and valuable suggestions.

Authors' contributions

All authors take part in the discussion of the work described in this paper. All authors read and approved the final manuscript.

\section{Funding}

This work was supported by Key Funding Project of Green Development Research Fund of Higher Education Ministry: Research on Intelligent Energy Conservation Strategy Based on Big Data (Educational Development 2016-07).

Availability of data and materials

Not applicable.

\section{Declarations}

Consent for publication

Approved.

\section{Competing interests}

There is no potential competitive advantage in our paper. All the authors have reviewed the manuscript and agreed to submit it to your magazine. We confirm that the contents of the manuscript have not been published or submitted for publication elsewhere.

\section{Author details}

${ }^{1}$ College of Electric Power, North China University of Water Resources and Electric Power, Zhengzhou 450045, Henan, China. ${ }^{2}$ Xi'an University of Architecture and Technology, Xi'an 710055, Shaanxi, China. 


\section{References}

1. Z. Lv, A. Halawani, S. Feng, H. Li, S.U. Réhman, Multimodal hand and foot gesture interaction for handheld devices. ACM Trans. Multimed. Comput. Commun. Appl. (TOMM) 11(1s), 1-19 (2014)

2. M. Zhou, Y. Wang, Z. Tian, Y. Lian, Y. Wang, B. Wang, Calibrated data simplification for energy-efficient location sensing in Internet of things. IEEE Internet Things J. 6(4), 6125-6133 (2019)

3. X. Xu, D. Cao, Y. Zhou et al., Application of neural network algorithm in fault diagnosis of mechanical intelligence. Mech. Syst. Signal Process. 141, 106625 (2020)

4. S. Maximov, V.H. Cori, F. Rivas-Davalos et al., New analytical method for estimating mean life of electric power equipment based on complete and right-censored failure data. Electr. Power Syst. Res. 154(1), 311-318 (2018)

5. Y.H. Yuan, S.H. Tsao, J.T. Chyou, S.B. Tsai, An empirical study on effects of electronic word-of-mouth and internet risk avoidance on purchase intention-from the perspective of big data. Soft Comput. 2020(24), 5713-5728 (2020)

6. J. Qiu, H. Wang, D. Lin et al., Nonparametric regression-based failure rate model for electric power equipment using lifecycle data. IEEE Trans. Smart Grid 6(2), 1-1 (2016)

7. M.H.B. Nozadian, M.S. Zarbil, M. Abapour, The effect of series and shunt redundancy on power semiconductor reliability. J. Power Electron. 16(4), 1426-1437 (2016)

8. W. Zhu, Z. Zhang, D. Chen, W. Chai, D. Chen, J. Zhang, C. Zhang, Y. Hao, Interfacial voids trigger carbon-based, allinorganic CsPbIBr 2 perovskite solar cells with photovoltage exceeding 1.33 V. Nano-micro Lett 12(1), 1-14 (2020). https://doi.org/10.1007/s40820-020-00425-1

9. J. Li, L. Bao, J. Zhang et al., Adequacy of dual-variable Weibull failure distribution for oil-impregnated paper under pulsating DC voltage. IEEE Trans. Dielectr. Electr. Insul. 23(3), 1555-1561 (2016)

10. G. Dartmann, H. Song, A. Schmeink, Big Data Analytics for Cyber-Physical Systems: Machine Learning for the Internet of Things (Elsevier, Amsterdam, 2019), pp. 1-360

11. Z. LV, N. Kumar, Software defined solutions for sensors in 6G/loE. Comput. Commun. 153,42-47 (2020)

12. G.V. Tomarov, A.A. Shipkov, Flow-accelerated corrosion wear of power-generating equipment: investigations, prediction, and prevention: 1. Flow-accelerated corrosion processes and regularities. Therm. Eng. 65(8), 493-503 (2018)

13. D. Khan, S.R. Samadder, Allocation of solid waste collection bins and route optimisation using geographical information system: a case study of Dhanbad City, India. Waste Manag. Res. 34(7), 666-676 (2016)

14. S. Wan, Z. Gu, Q. Ni, Cognitive computing and wireless communications on the edge for healthcare service robots. Comput. Commun. (2019). https://doi.org/10.1016/j.comcom.2019.10.012

15. Y. Xu, X. Gu, B. Liu et al., Special requirements of high frequency current transformers in the on-line detection of partial discharges in power cables. IEEE Electr. Insul. Mag. 32(6), 8-19 (2016)

16. J. Zhong, W. Li, C. Wang et al., Determining optimal inspection intervals in maintenance considering equipment aging failures. IEEE Trans. Power Syst. 32(2), 1474-1482 (2016)

17. Z. Lv, D. Chen, R. Lou, Q. Wang, Intelligent edge computing based on machine learning for smart city. Future Gen. Comput. Syst. 115, 90-99 (2020)

18. Z. LV, H. Song, Mobile internet of things under data physical fusion technology. IEEE Internet Things J. 7, 4616-4624 (2019)

19. Z. Yushu, H. Qi, C. Guo, Z. Xinpeng, X. Yong, (2019) A low-overhead, confidentiality-assured, and authenticated data acquisition framework for loT. IEEE Trans. Ind. Inform. 16, 7566-7578 (2019)

20. O.V. Goryunov, S.V. Slovtsov, V.E. Mikhailov et al., Justifying the vibration resistance of pipelines of NPPS. Power Technol. Eng. 52(3), 325-327 (2018)

21. B. Wang, X. Wang, Z. Bie et al., Reliability model of MMC considering periodic preventive maintenance. IEEE Trans. Power Deliv. 32(3), 1535-1544 (2017)

22. Y. Huang, P. Swamidass, D.A. Raju, The nature of innovation in emerging industries in China: an exploratory study. J. Technol. Transf. 41(3), 451-468 (2016)

23. P. Sun, C. Gong, X. Du et al., Online condition monitoring for both IGBT module and DC-link capacitor of power converter based on short-circuit current simultaneously. IEEE Trans. Ind. Electron. 64(5), 3662-3671 (2017)

24. S.T. Li, J.Q. He, J.J. Lin et al., Electrical-thermal failure of metal-oxide arrester by successive impulses. IEEE Trans. Power Deliv. 31(6), 2538-2545 (2016)

25. J. Yang, W. Feng, X. Hou et al., A distributed cooperative control algorithm for optimal power flow and voltage regulation in DC power system. IEEE Trans. Power Deliv. 35(2), 892-903 (2020)

26. Y. Tang, F. Li, Q. Wang et al., Quantitative evaluation of communication system fault effect on real-time load control of power system. Electr. Power Autom. Equip. 37(2), 90-96 (2017)

27. X. Zhang, Comparative analysis on power equipment maintenance strategies considering the effect of operating conditions. Power Syst. Protect. Control 45(1), 74-80 (2017)

28. T. Wang, Q. Wang, P. Wang, Three-dimensional thermal modelling of transformers in transformer room for spatial and temporal failure analysis. IET Gener. Transm. Distrib. 12(13), 3314-3321 (2018)

29. X. Chen, J. Tang, W. Li, Probabilistic operational reliability of composite power systems considering multiple meteorological factors. IEEE Trans. Power Syst. 35(1), 85-97 (2020)

30. P. Sun, Z. Tian, Z. Wang et al., PRSS: a prejudiced random sensing strategy for energy-efficient information collection in the internet of things. IEEE Internet Things J. 6(2), 2717-2728 (2019)

31. C. Anagnostopoulos, Intelligent contextual information collection in internet of things. Int. J. Wirel. Inf. Netw. 23(1), $1-12(2016)$

32. C. Chen, X. Xu, Design and application of traceability and supervision platform for broiler based on Internet of Things. Trans. Chin. Soc. Agric. Eng. 33(5), 224-231 (2017) 
33. H. Duan, Y. Zheng, C. Wang et al., Treasure collection on Foggy islands: building secure network archives for internet of things. IEEE Internet Things J. 6(2), 2637-2650 (2019)

34. Z. Xiao, H. Dong, L. Bai et al., Unmanned aerial vehicle base station (UAV-BS) deployment with millimeter-wave beamforming. IEEE Internet Things J. 7(2), 1336-1349 (2020)

35. A. Mohajerani, D. Gharavian, An ant colony optimization based routing algorithm for extending network lifetime in wireless sensor networks. Wirel. Netw. 22(8), 2637-2647 (2016)

36. G. Bardhoshi, B.D. Jordre, W.E. Schweinle et al., Understanding exercise practices and depression, anxiety, and stress in senior games athletes. Top. Geriatr. Rehabil. 32(1), 63-71 (2016)

\section{Publisher's Note}

Springer Nature remains neutral with regard to jurisdictional claims in published maps and institutional affiliations.
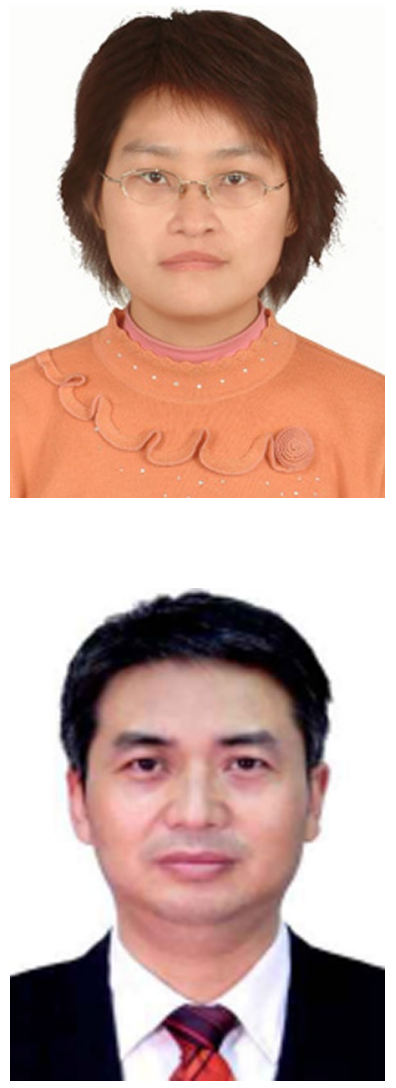

Ruilian Wang was born in Henan, Nanyang, China, in 1976.She received the master's degree from HHO University, People's Republic of China. Now, she works in North China University of Water Resources and Electric Power. Her research interest include comprehensive evaluation of water resources and hydropower, stability operation analysis of hydropower unit, fault diagnosis technology of water conservancy and electric equipment mathematical modeling and so on.

Minghai Li was born in Shaanxi, People's Republic of China, in 1971. He received the doctor's degree from Xi'an University of Architecture and Technology, People's Republic of China. Now, he works in Xi'an University of Architecture and Technology. His research interest include control engineering, intelligent building and electric power system analysis.

\section{Submit your manuscript to a SpringerOpen ${ }^{\circ}$ journal and benefit from:}

- Convenient online submission

Rigorous peer review

- Open access: articles freely available online

- High visibility within the field

Retaining the copyright to your article 